\title{
Hemodynamic responses to simulated weightlessness of 24-h head-down bed rest and KAATSU blood flow restriction
}

\author{
Toshiaki Nakajima $\cdot$ Haruko Iida $\cdot$ Miwa Kurano $\cdot$ Haruhito Takano \\ Toshihiro Morita · Kentaro Meguro · Yoshiaki Sato · Yoshihisa Yamazaki · \\ Sino Kawashima $\cdot$ Hiroshi Ohshima $\cdot$ Shouichi Tachibana $\cdot$ Naokata Ishii · \\ Takashi Abe
}

Accepted: 10 July 2008/Published online: 24 July 2008

(C) The Author(s) 2008

\begin{abstract}
The KAATSU training is a unique method of muscle training with restricting venous blood flow, which might be applied to prevent muscle atrophy during space flight, but the effects of KAATSU in microgravity remain unknown. We investigated the hemodynamic responses to KAATSU during actually simulated weightlessness $\left(6^{\circ}\right.$ head-down tilt for $24 \mathrm{~h}, n=8$ ), and compared those to KAATSU in the seated position before bed rest. KAATSU was applied to the proximal ends of both the thighs. In the seated position before bed rest, sequential incrementing of KAATSU cuff pressure and altering the level of blood flow restriction resulted in a decrease in stroke volume (SV) with an increase in heart rate (HR). KAATSU (150$200 \mathrm{mmHg}$ ) decreased SV comparable to standing.
\end{abstract}

T. Nakajima $(\bowtie) \cdot$ H. Iida · M. Kurano · H. Takano · Y. Sato Department of Ischemic Circulatory Physiology,

KAATSU Training, University of Tokyo, 7-3-1 Hongo,

Bunkyo-ku, Tokyo 113-8655, Japan

e-mail: masamasa@pb4.so-net.ne.jp

T. Morita $\cdot$ K. Meguro

Department of Cardiovascular Medicine, University of Tokyo,

Tokyo, Japan

Y. Yamazaki

Japan Manned Space Systems Corporation, Tokyo, Japan

S. Kawashima $\cdot$ H. Ohshima $\cdot$ S. Tachibana

Japan Aerospace Explosion Agency, Tsukuba, Japan

N. Ishii

Department of Life Sciences, Graduate School of Arts

and Sciences, University of Tokyo, Tokyo, Japan

T. Abe

Department of Human and Engineered Environmental Studies, Graduate School of Frontier Science, The University of Tokyo, Chiba, Japan
Following 24-h bed rest, body mass, blood volume (BV), plasma volume (PV), and diameter of the inferior vena cava (IVC) were significantly reduced. Norepinephrine (NOR), vasopressin (ADH), and plasma renin activity (PRA) tend to be reduced. A decrease in SV and CO induced by KAATSU during the simulated weightlessness was larger than that in the seated position before bed rest, and one of eight subjects developed presyncope due to hypotension during $100 \mathrm{mmHg}$ KAATSU. High-frequency power $\left(\mathrm{HF}_{\mathrm{RR}}\right)$ decreased during KAATSU and standing, while low-frequency/high-frequency power $\left(\mathrm{LF}_{\mathrm{RR}} / \mathrm{HF}_{\mathrm{RR}}\right)$ increased significantly. NOR, ADH and PRA also increased during KAATSU. These results indicate that KAATSU blood flow restriction reproduces the effects of standing on HR, SV, NOR, ADH, PRA, etc., thus stimulating a gravity-like stress during simulated weightlessness. However, syncope due to lower extremity blood pooling and subsequent reduction of venous return may be induced during KAATSU in microgravity as reported in cases of lower-body negative pressure.

Keywords KAATSU training - Autonomic function . Space flight . Cardiovascular deconditioning . $6^{\circ}$ head-down tilt bed rest . Sympathetic activity

\section{Introduction}

The weightless environment of space flight causes serious adaptive changes in cardiovascular function as well as muscle atrophy. A shift in blood volume from lower-body capacitance vessels toward the head and elevation of tissue capillary perfusion pressure in the head causes facial and intracranial edema and headache, which distresses astronauts. And, nearly all crew members develop cardiovascular 
deconditioning characterized by orthostatic intolerance and reduced upright exercise capacity, which is manifest after space flight (Nicogossian et al. 1995; Buckey et al. 1996; Fritsch-Yelle et al. 1996). The mechanisms involved in this deconditioning include hypovolemia, decreased baroreflex responsiveness, and decreased skeletal muscle stiffness. Therefore, effective countermeasures during spaceflight are needed to maintain the cardiovascular system, as well as the musculoskeletal structure-function to ensure the wellbeing and safety of crew members during space flight and upon return to Earth.

An elastic thigh cuff, called "bracelets", has been reported to be an effective passive countermeasure for reducing edema and venous stasis in the cephalic region by pooling blood in the vascular and extravascular compartments of the legs, easing the stress of zero gravity (Lindgren et al. 1998; Arbeille et al. 1999; Millet et al. 2000). However, the effectiveness of bracelets to prevent cardiovascular deconditioning is incomplete, providing only partial compensation for the cardiovascular changes (Herault et al. 2000). The most effective countermeasure for preventing cardiovascular deconditioning appears to be imposition of a gravity-like stress, such as lower-body negative pressure (LBNP) (Güell et al. 1990, 1992; Lathers and Charles 1993). When combined with intensive exercise, LBNP is a potent orthostatic stimulus, which presumably provides an effective prevention of orthostatic intolerance following space flight (Lee et al. 1997; Watenpaugh et al. 2000). However, a large-scale apparatus combined with exercise machine is required. In addition, LBNP can be combined with treadmill (Murthy et al. 1994), but not resistance-type machines. The use of resistance exercises may be essential to prevent muscle atrophy during space flight as resistance training specifically promotes muscle enlargement and muscular strength, which are negatively impacted by weightlessness. Thus, if a method of exercise with a potent orthostatic stimulus like LBNP exists, it may provide an effective countermeasure for cardiovascular deconditioning as well as muscle atrophy in weightlessness.

The key physiological features of LBNP are lower extremity blood pooling, reduction of venous return to the heart, and subsequent hemodynamic changes including increased autonomic nervous system activation (Stevens and Lamb 1965; Tomaselli et al. 1987; Lathers and Charles 1993). The KAATSU training is a unique technique of performing low-load exercises such as resistance exercises and treadmill with restricted muscle blood flow that results in an increase in muscle mass and muscular strength comparable to high-intensity training (Takarada et al. 2000; Abe et al. 2006; Fujita et al. 2007). Since KAATSU femoral blood flow restriction induces the retention of blood flow in lower extremities, it reduces venous return, and induces subsequent hemodynamic changes such as decreased SV and CO and increased TPR like LBNP (Stevens and Lamb 1965; Güell et al. 1990, 1992; Melchior et al. 1994; Murthy et al. 1994; Lee et al. 1997; Watenpaugh et al. 2000; Iida et al. 2007). Thus, KAATSU may partly provide an orthostatic stimulus, and an effective countermeasure for cardiovascular deconditioning in weightlessness like LBNP. However, the potency of KAATSU for inducing pooling of venous blood and then hemodynamic changes in microgravity has not been investigated. In addition, the occurrence of syncopal attack has been reported in cases of LBNP, especially when using high pressure more than $40 \mathrm{mmHg}$ (Stevens and Lamb 1965), but the safety of KAATSU in microgravity remain unclear.

Therefore, the aim of this study is to examine the hemodynamic responses to KAATSU during actually simulated weightlessness $\left(6^{\circ}\right.$ head-down tilt for $\left.24 \mathrm{~h}\right)$, and to compare those to KAATSU in the seated position before bed rest. In addition, the potency for inducing pooling of venous blood and then hemodynamic changes during KAATSU is compared to those reported during LBNP.

\section{Materials and methods}

\section{Subjects}

Eight males (age $32.8 \pm 1.0$ years; height $176 \pm 16 \mathrm{~cm}$; weight $75.3 \pm 3.9 \mathrm{~kg}$ ) participated in the following experiments. All subjects were healthy, free of neuromuscular or cardiovascular disease, were not on any medication, and none had a specific history of physical exercise training. This investigation was approved by the institutional review board (IRB) of human research of Japan Aerospace Explosion Agency (JAXA) and the ethics committee of the University of Tokyo, and all subjects gave their informed consent prior to inclusion.

\section{Experimental protocol}

This study consisted of two experiments as summarized in Fig. 1. All experiments were separated by 1-2 weeks, and were performed at the Japanese Aerospace Explosion Agency between 25 September and 26 October in 2006.

\section{Experiment A}

As shown in Fig. 1a, to mimic KAATSU training on Earth, the effects of sequential incrementing of KAATSU cuff pressure $(50 \mathrm{mmHg}$ step) on hemodynamic parameters in the seated position were examined in the morning. After a 30-min rest in the seated position, we took rest measurements of hemodynamic parameters at this position for 


\section{A KAATSU (sitting)}

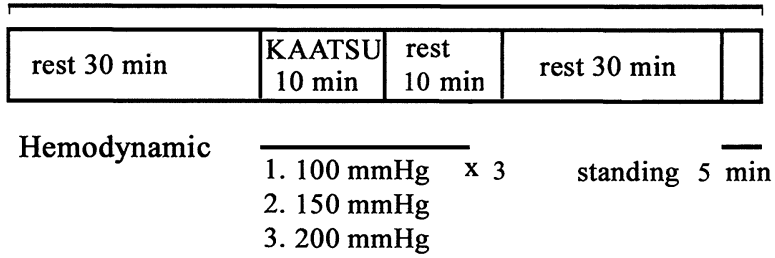

B KAATSU ( $24 \mathrm{~h}$ bed rest)

\begin{tabular}{l|l|r|r|r|}
\hline rest $30 \mathrm{~min}$ & $\begin{array}{c}\text { KAATSU } \\
10 \mathrm{~min}\end{array}$ & $\begin{array}{c}\text { rest } \\
10 \mathrm{~min}\end{array}$ & rest $30 \mathrm{~min}$ & \\
\cline { 2 - 4 } & $\begin{array}{l}\text { 1. } 50 \mathrm{mmHg} \times 2 \\
\text { 2. } 100 \mathrm{mmHg}\end{array}$ & standing $5 \mathrm{~min}$ \\
& \\
Blood sample \\
Hemodynamic \\
ECHO
\end{tabular}

Fig. 1 Experimental design. a KAATSU in the seated position (mimic KAATSU on Earth) b simulated weightlessness and KAATSU (mimic KAATSU on space)

5 min by using an impedance cardiography. Then, both the proximal thighs were pressure-applied with the specially designed belt developed for spaceflight (see below). After recording the hemodynamic parameters for $10 \mathrm{~min}$ under $100 \mathrm{mmHg}$ KAATSU, the banding pressure was released and the hemodynamic parameters were continuously taken during a 5-10 min recover time. After the additional $30 \mathrm{~min}$ rest in the seated position, the effects of $150 \mathrm{mmHg}$ KAATSU on hemodynamic parameters were investigated. Similarly, we repeated the experiments of KAATSU $(200 \mathrm{mmHg})$. Finally, the effects of standing on hemodynamic parameters were also investigated. During the first experiment, nobody complained of any symptoms including syncopal attack.

\section{Experiment $B$}

This experiment was designed to investigate the effects of KAATSU on hemodynamic parameters during the weightlessness, which was simulated for $24 \mathrm{~h}$ using bed rest with a $6^{\circ}$ head-down tilt. Subjects maintained $6^{\circ}$ headdown tilt position during the entire bed rest period. Transportation and toilet procedures were restricted to the head-down recumbent position. Subjects were allowed to rest on their elbows during meals and could move volitionally but remained horizontal to the bed. To ensure compliance, the volunteers were monitored at all times by video-camera surveillance. Subject's diet, fluid intake, and urine volume were also monitored.
The control echocardiographic data, and blood samples were collected after $10 \mathrm{~min}(0-\mathrm{h}$ bed rest) after bed rest. After $24 \mathrm{~h}$ after bed rest (24-h bed rest), the effects of KAATSU on hemodynamic parameters were examined while maintaining the head-down tilt and bed rest position. Control hemodynamic parameters after 24-h bed rest were monitored continuously for $5 \mathrm{~min}$, followed by echocardiography and collection of blood samples. Then, hemodynamic responses to KAATSU were studied at two levels of KAATSU belt pressure (50 and $100 \mathrm{mmHg}$ ). The following timing pattern was employed: apply KAATSU, 10 min continuous hemodynamic measurement, remove KAATSU, and record an additional 10 min of continuous hemodynamic response, then rest without KAATSU for $30 \mathrm{~min}$. The KAATSU pressure was first set to $100 \mathrm{mmHg}$, but the first subject complained of presyncopal attack and was excluded from the following experiments and data analysis. Therefore, the remaining subjects $(n=7)$ began with a lower KAATSU cuff pressure $(50 \mathrm{mmHg})$ prior to $100 \mathrm{mmHg}$. After completing the two KAATSU pressure trials in bed rest position, subject stood up and hemodynamic response was recorded continuously for $5 \mathrm{~min}$ in standing position. We had not examined $150 \mathrm{mmHg}$ due to the marked decrease in SV during $100 \mathrm{mmHg}$. With each pressure perturbation, blood samples were collected immediately following release of KAATSU (0-1 min), and $30 \mathrm{~min}$ after the release. The data obtained from seven subjects who completely finished both experiments were shown.

\section{Methods}

\section{KAATSU blood flow restriction}

Femoral blood flow was impaired using the KAATSU technique, which restricts venous blood flow and causes pooling of blood in capacitance vessels distal to the cuff (Takarada et al. 2000; Takano et al. 2005; Abe et al. 2006; Fujita et al. 2007; Iida et al. 2007). KAATSU was applied to the proximal end of both the thighs as near to the hip joint as possible by using KAATSU belts $(65 \mathrm{~mm}$ in width and $650 \mathrm{~mm}$ in length). The cuff pressure was controlled by the KAATSU apparatus as previously described (Iida et al. 2007).

\section{Cardiovascular hemodynamics}

Hemodynamic parameters were determined using the Task Force Monitor (CNSystmes Medizintechnik, Graz, Austria) as previously described (Takano et al. 2005; Iida et al. 2007). Analysis included electrocardiograms (ECG), impedance cardiography, beat-to-beat blood pressure by vascular unloading technique and oscillometric blood 
pressure. Data were obtained for every beat with a $1,000 \mathrm{~Hz}$ sampling rate and used to calculate all hemodynamic parameters in real time. Data included heart rate (HR; bpm), mean arterial blood pressure (mAP; mmHg), systolic blood pressure (sBP), diastolic blood pressure $(\mathrm{dBP})$, stroke volume (SV; ml), cardiac output (CO; $1 / \mathrm{min})$ and total peripheral resistance (TPR; dyne $\mathrm{s} \mathrm{cm}^{-5}$ ). TPR was calculated in relative units as MAP.CO ${ }^{-1}$, and the calculation of CO and TPR was as follows.

$\mathrm{CO}=\mathrm{SV} \times \mathrm{HR}$

$\mathrm{TPR}=\mathrm{MAP} \times 80 \times \mathrm{CO}^{-1}$

Histograms of RR intervals were computed and pseudodigitized at ten samples per second. Auto-regressive modeling (Burg method) was used to construct frequency domain spectrograms of the heart rate variability (HRV). Parameters extracted from the variability spectra were lowfrequency power $\left(\mathrm{LF}_{\mathrm{RR}}, 0.03-0.15 \mathrm{~Hz}\right)$ and high-frequency power $\left(\mathrm{HF}_{\mathrm{RR}}, 0.16-0.50 \mathrm{~Hz}\right)$, normalized to total power over the range from 0.01 to $0.50 \mathrm{~Hz}$.

\section{Cardiac dimensions}

Trans-thoracic echocardiography was performed using Aplio80. Left ventricular end-systolic dimension (LVDs; $\mathrm{mm}$ ), left ventricular end-diastolic dimension (LVDd; $\mathrm{mm}$ ) and the diameter of inferior vena cava (IVC; $\mathrm{cm}$ ) were determined using the M-mode recording in the parasternal long-axis view with the pulsed wave as described previously (Iida et al. 2007).

\section{Hormone-metabolite levels}

Venous blood samples were collected and analyzed for hematocrit, hemoglobin, noradrenaline, plasma renin activity and vasopressin. Blood sample was accomplished with an indwelling catheter inserted into the superficial antebrachial vein of left arm. For measurement of hemoglobin and hematocrit, $2 \mathrm{ml}$ of blood was placed into test tubes containing EDTA-2Na. For hormone determination, blood (7 ml) was placed in test tubes containing $10.5 \mathrm{mg}$ of EDTA$2 \mathrm{Na}$. All samples were kept in ice-cold water and centrifuged $(3,000 \mathrm{rpm})$ for $10 \mathrm{~min}$ and the plasma was stored at $-20^{\circ} \mathrm{C}$ until the assays were performed. Blood hemoglobin $(\mathrm{Hb}$, $\mathrm{g} \mathrm{dl}^{-1}$ ) was determined by the cyanomethemoglobin method (Coulter hemoglobinometer) and hematocrit (Hct, \%) by the micro-hematocrit ultra centrifugation technique. Plasma concentrations of noradrenaline (NOR; lower limit of detection $6 \mathrm{pg} \mathrm{ml}^{-1}$ ) were measured using high performance liquid chromatography. Plasma renin activity (PRA; lower limit of detection $0.1 \mathrm{ng} \mathrm{ml}^{-1} \mathrm{~h}^{-1}$ ) and vasopressin $\left(\mathrm{ADH}\right.$; lower limit of detection $0.2 \mathrm{pg} \mathrm{ml}^{-1}$ ) were determined by radioimmunoassay. These assays were completed at commercially available laboratories (SRL Inc., Tokyo, Japan).

Changes in blood and plasma volume (\%) were derived from the following equation;

$$
\begin{aligned}
& \mathrm{BV}_{\mathrm{B}} \times \mathrm{BV}_{\mathrm{A}}^{-1}=\mathrm{Hb}_{\mathrm{A}} \times \mathrm{Hb}_{\mathrm{B}}^{-1} \\
& \% \Delta \mathrm{PV}= 100 \times\left(\mathrm{Hb}_{\mathrm{B}} \times \mathrm{Hb}_{\mathrm{A}}^{-1}\right) \\
& \times\left(\left(1-\mathrm{Hct}_{\mathrm{A}} \times 10^{-2}\right) /\left(1-\mathrm{Hct}_{\mathrm{B}} \times 10^{-2}\right)\right) \\
&-100
\end{aligned}
$$

where $A$ is the initial value and $B$ is the value at the corresponding time.

\section{Data analysis}

All values are expressed as means \pm SEM Student's paired $t$-test was used to compare two sets of data from the same subjects. Comparison of time courses of parameters was analyzed by one-way ANOVA for repeated measures. When differences were indicated, a Bonferroni's comparison was used to determine significance. Differences were considered significant if $P<0.05$.

\section{Results}

Table 1 shows the hemodynamic changes during KAATSU (100-200 $\mathrm{mmHg}$ ) in the seated position and the standing position before bed rest. The pressurization of 100$200 \mathrm{mmHg}$ significantly increased HR, and decreased SV, which depended on the pressure. $200 \mathrm{mmHg}$ KAATSU increased HR from $64.8 \pm 3.2$ to $74.0 \pm 4.0 \mathrm{bpm}(n=7$, $P<0.01)$. After the release of pressure, HR promptly returned to the pre test level. The pressurization of $200 \mathrm{mmHg}$ decreased SV from $73.6 \pm 3.5$ to $60.2 \pm 2.2 \mathrm{ml}$ ( $n=7, P<0.01$ ). After an orthostatic stress (standing), HR increased with decreasing SV. The decrease in SV observed during 150-200 $\mathrm{mmHg}$ was lower than that in the standing position $(66.9 \pm 2.4 \mathrm{ml})$. $\mathrm{CO}$ did not significantly change during KAATSU in the seated position before bed rest. TPR, $\mathrm{sBP}, \mathrm{mBP}$, and $\mathrm{dBP}$ were also not significantly altered during KAATSU.

Following $24 \mathrm{~h}$ of $6^{\circ}$ head-down tilt bed rest, there was a $2.0 \mathrm{~kg}$ decease in body mass $(75.3 \pm 3.9$ to $73.3 \pm 3.8 \mathrm{~kg}$, $n=7, P<0.01$ ) associated with a significant urine output $\left(2052 \pm 249 \mathrm{ml} \mathrm{d}^{-1}\right)$ that markedly exceeded water intake $\left(1320 \pm 67 \mathrm{ml} \mathrm{d}^{-1}\right)$. After $24 \mathrm{~h}$ of $6^{\circ}$ head-down tilt bed rest, blood $(4.4 \pm 1.4 \%)$ and plasma $(7.9 \pm 2.5 \%)$ volume decreased as Hct $(46.4 \pm 1.2 \%$ to $48.5 \pm 0.8 \%, P<0.01)$ and $\mathrm{Hb}(15.0 \pm 0.3$ to $15.7 \pm 0.3 \mathrm{mg} / \mathrm{dl}, P<0.01)$ significantly increased. 
Table 1 Hemodynamic responses during KAATSU in the seated position

\begin{tabular}{llllllll}
\hline & $\mathrm{HR}(\mathrm{bpm})$ & $\mathrm{sBP}(\mathrm{mmHg})$ & $\mathrm{mBP}(\mathrm{mmHg})$ & $\mathrm{dBP}(\mathrm{mmHg})$ & $\mathrm{SV}(\mathrm{ml})$ & $\mathrm{CO}\left(1 \mathrm{~min}^{-1}\right)$ & $\left.\mathrm{TPR}_{(\mathrm{dyne} \mathrm{s} \mathrm{cm}}^{-5}\right)$ \\
\hline Pre & $68.8 \pm 3.1$ & $122.9 \pm 6.8$ & $93.8 \pm 4.6$ & $81.5 \pm 4.0$ & $74.8 \pm 3.1$ & $5.1 \pm 0.3$ & $1459 \pm 103$ \\
100 & $70.2 \pm 3.7^{* *}$ & $118.5 \pm 6.4$ & $93.0 \pm 5.2$ & $82.5 \pm 4.6$ & $67.7 \pm 2.9^{* *}$ & $4.7 \pm 0.3$ & $1570 \pm 128$ \\
Post & $69.7 \pm 3.7$ & $124.4 \pm 5.7$ & $97.4 \pm 4.5$ & $85.4 \pm 3.7$ & $67.5 \pm 3.6^{* *}$ & $4.7 \pm 0.3$ & $1679 \pm 135$ \\
Pre & $65.5 \pm 3.2$ & $122.0 \pm 6.5$ & $96.0 \pm 4.9$ & $83.3 \pm 4.4$ & $71.0 \pm 3.8$ & $4.6 \pm 0.3$ & $1689 \pm 168$ \\
150 & $72.3 \pm 3.6^{* *}$ & $123.9 \pm 4.5$ & $95.4 \pm 3.8$ & $84.4 \pm 3.5$ & $63.5 \pm 2.5^{* *}$ & $4.6 \pm 0.3$ & $1664 \pm 123$ \\
Post & $67.4 \pm 3.5$ & $125.4 \pm 4.5$ & $94.6 \pm 3.2$ & $82.1 \pm 3.8$ & $69.9 \pm 3.8$ & $4.7 \pm 0.3$ & $1638 \pm 120$ \\
Pre & $64.8 \pm 3.2$ & $124.1 \pm 4.7$ & $93.9 \pm 4.1$ & $82.6 \pm 3.9$ & $73.6 \pm 3.5$ & $4.8 \pm 0.3$ & $1576 \pm 114$ \\
200 & $74.0 \pm 4.0^{* *}$ & $124.2 \pm 5.2$ & $97.6 \pm 3.9$ & $86.6 \pm 3.5$ & $60.2 \pm 2.2^{* *}$ & $4.4 \pm 0.3$ & $1758 \pm 126$ \\
Post & $67.3 \pm 3.2$ & $124.4 \pm 4.5$ & $99.3 \pm 3.8$ & $86.2 \pm 3.2$ & $68.2 \pm 3.2^{* *}$ & $4.5 \pm 0.3$ & $1758 \pm 111$ \\
Pre & $66.7 \pm 2.8$ & $125.9 \pm 6.0$ & $98.8 \pm 4.8$ & $85.1 \pm 4.1$ & $68.2 \pm 2.2$ & $4.5 \pm 0.3$ & $1723 \pm 109$ \\
Stand & $71.4 \pm 3.4 * *$ & $129.6 \pm 5.7 *$ & $104.5 \pm 4.5^{*}$ & $91.6 \pm 4.2^{*}$ & $66.9 \pm 2.4^{* *}$ & $4.7 \pm 0.2$ & $1753 \pm 109$ \\
\hline
\end{tabular}

* $P<0.05$ versus Pre

** $P<0.01$ versus Pre

There was a significant decrease in the diameter of IVC $(1.71 \pm 0.13 \mathrm{~cm}$ to $1.34 \pm 0.12 \mathrm{~cm}, P<0.05, n=7)$ following $24 \mathrm{~h}$ of head-down tilt bed rest $(P<0.05)$ that was associated with the reduced plasma volume and then venous return. The diameter of LVDd $(51.6 \pm 1.3$ to $51.2 \pm 1.1 \mathrm{~mm}$ ) was not significantly altered by $24 \mathrm{~h}$ of head-down tilt bed rest. HR $(59.2 \pm 4.0$ to $58.9 \pm 3.7 \mathrm{bpm})$, and sBP $(121.9 \pm 5.1$ to $126.0 \pm 5.6 \mathrm{mmHg})$ were also not altered by $24 \mathrm{~h}$ of head-down bed rest.

The serum concentration of PRA $(1.51 \pm 0.48$ to $\left.0.86 \pm 0.18 \mathrm{ng} \mathrm{ml}^{-1} \mathrm{~h}^{-1}, \quad n=7, \quad P=0.08\right), \quad$ ADH $\left(1.81 \pm 0.26\right.$ to $\left.1.50 \pm 0.12 \mathrm{pg} \mathrm{ml}^{-1}, P=0.08\right)$, NOR (201 \pm 45 to $\left.157 \pm 24 \mathrm{pg} \mathrm{ml}^{-1}, P=0.09\right)$, and DOP $\left(7.1 \pm 1.5\right.$ to $\left.5.4 \pm 0.4 \mathrm{pg} \mathrm{ml}^{-1}, P=0.09\right)$ tended to decrease following $24 \mathrm{~h}$ of $6^{\circ}$ head-down tilt bed rest.

During experiment $\mathrm{B}$, one subject complained of dizziness and developed neurocirculatory presyncope because of hypotension, $\sim 5 \mathrm{~min}$ after $100 \mathrm{mmHg}$ KAATSU. No other symptoms were articulated or observed in the remaining seven subjects for the duration of the experiment.
IVC was significantly reduced by KAATSU at $50 \mathrm{mmHg} \quad(1.34 \pm 0.12$ to $1.09 \pm 0.09 \mathrm{~cm}, \quad n=7$, $P<0.05$ ), and $100 \mathrm{mmHg}$ (to $1.05 \pm 0.15 \mathrm{~cm}, n=7$, $P<0.05)$. LVDd was reduced with both $50 \mathrm{mmHg}$ KAATSU (51.2 \pm 1.1 to $46.4 \pm 1.3 \mathrm{~mm}, P<0.01)$ and $100 \mathrm{mmHg}$ KAATSU (to $45.44 \pm 1.63 \mathrm{~mm}, P<0.01$ ).

SV (Table 2) was significantly reduced by KAATSU at $50 \mathrm{mmHg}(88.0 \pm 5.3$ to $68.5 \pm 3.9 \mathrm{ml}, P<0.01)$ and $100 \mathrm{mmHg}(84.8 \pm 4.5$ to $58.3 \pm 3.3 \mathrm{ml}, \quad P<0.01)$. Although there was a significant increase in HR, CO was significantly reduced at each level of KAATSU. SV, HR, and $\mathrm{CO}$ returned to pre-KAATSU levels immediately after the release of KAATSU (data not shown). There were no changes in $\mathrm{Hct}, \mathrm{Hb}, \mathrm{BV}$, or PV associated with KAATSU blood flow restriction $(50,100 \mathrm{mmHg}$; Table 3). Upon standing, SV decreased $(82.7 \pm 4.7$ to $54.4 \pm 2.1 \mathrm{ml}$, $P<0.01$ ); a decrement comparable to $100 \mathrm{mmHg}$ KAATSU. The significant increase in HR upon standing was greater than that observed during KAATSU, and thus, CO was maintained during standing (Table 2). TPR increased at each level of KAATSU, but was significantly less than

Table 2 Hemodynamic responses during KAATSU following 24-h bed rest

\begin{tabular}{llllllll}
\hline & $\mathrm{HR}(\mathrm{bpm})$ & $\mathrm{sBP}(\mathrm{mmHg})$ & $\mathrm{mBP}(\mathrm{mmHg})$ & $\mathrm{dBP}(\mathrm{mmHg})$ & $\mathrm{SV}(\mathrm{ml})$ & $\mathrm{CO}\left(1 \mathrm{~min}^{-1}\right)$ & $\left.\mathrm{TPR}(\mathrm{dyne} \mathrm{s} \mathrm{cm})^{-5}\right)$ \\
\hline Pre & $58.9 \pm 3.7$ & $126.0 \pm 5.6$ & $93.3 \pm 3.2$ & $79.4 \pm 2.5$ & $88.0 \pm 5.3$ & $5.2 \pm 0.6$ & $1480 \pm 145$ \\
50 & $62.8 \pm 4.0^{* *}$ & $122.8 \pm 5.2$ & $89.0 \pm 3.6$ & $75.7 \pm 3.1$ & $68.5 \pm 3.9 * *$ & $4.3 \pm 0.5 * *$ & $1732 \pm 157^{* *}$ \\
Post & $58.0 \pm 4.0$ & $122.8 \pm 5.9$ & $91.1 \pm 3.8$ & $76.0 \pm 3.0$ & $87.2 \pm 5.4$ & $5.1 \pm 0.6$ & $1485 \pm 143$ \\
Pre & $56.3 \pm 4.2$ & $123.7 \pm 4.3$ & $91.6 \pm 3.5$ & $79.0 \pm 3.0$ & $84.8 \pm 4.5$ & $4.8 \pm 0.6$ & $1605 \pm 211$ \\
100 & $67.3 \pm 3.3 * *$ & $119.7 \pm 3.3$ & $89.2 \pm 2.1$ & $76.7 \pm 1.9$ & $58.3 \pm 3.3 * *$ & $3.9 \pm 0.4 * *$ & $1878 \pm 166^{*}$ \\
Post & $58.6 \pm 3.0$ & $124.2 \pm 6.8$ & $92.4 \pm 5.2$ & $77.6 \pm 4.0$ & $79.3 \pm 5.8$ & $4.7 \pm 0.6$ & $1668 \pm 211$ \\
Pre & $58.5 \pm 3.1$ & $124.7 \pm 5.3$ & $95.6 \pm 3.7$ & $82.8 \pm 3.9$ & $82.7 \pm 4.7$ & $4.8 \pm 0.6$ & $1657 \pm 186$ \\
Stand & $77.9 \pm 3.9 * *$ & $129.0 \pm 7.3$ & $104.5 \pm 6.5 *$ & $91.4 \pm 7.0$ & $54.4 \pm 2.1 * *$ & $4.3 \pm 0.3$ & $1996 \pm 189 *$ \\
\hline
\end{tabular}

* $P<0.05$ versus Pre

** $P<0.01$ versus Pre 
Table 3 Hemostatic responses during KAATSU following 24-h bed rest

\begin{tabular}{lllllllc}
\hline & $\mathrm{Hb}\left(\mathrm{mg} \mathrm{dl}^{-1}\right)$ & $\mathrm{Hct}(\%)$ & $\mathrm{BV}(\% \Delta)$ & $\mathrm{PV}(\% \Delta)$ & $\mathrm{NOR}\left(\mathrm{pg} \mathrm{ml}^{-1}\right)$ & $\mathrm{PRA}\left(\mathrm{ng} \mathrm{ml} \mathrm{h}^{-1}\right)$ & $\left.\mathrm{ADH}_{(\mathrm{pg} \mathrm{ml}}^{-1}\right)$ \\
\hline Pre & $15.7 \pm 0.25$ & $48.5 \pm 0.75$ & $-4.4 \pm 1.4$ & $-7.9 \pm 2.5$ & $157 \pm 24$ & $0.86 \pm 0.18$ & $1.5 \pm 0.12$ \\
50 & $15.7 \pm 0.25$ & $48.2 \pm 0.77$ & $-3.9 \pm 1.5$ & $-6.4 \pm 2.5$ & $211 \pm 35^{* *}$ & $0.94 \pm 0.14$ & $1.9 \pm 0.18$ \\
Pre & $15.6 \pm 0.26$ & $47.9 \pm 0.81$ & $-3.6 \pm 1.3$ & $-5.5 \pm 2.4$ & $148 \pm 20$ & $0.77 \pm 0.13$ & $1.39 \pm 0.17$ \\
100 & $15.8 \pm 0.21$ & $48.4 \pm 0.63$ & $-4.7 \pm 1.7$ & $-7.5 \pm 2.9$ & $235 \pm 41^{* *}$ & $1.09 \pm 0.20^{* *}$ & $2.2 \pm 0.62^{*}$ \\
Post & $15.6 \pm 0.25$ & $48.0 \pm 0.74$ & $-3.6 \pm 1.4$ & $-5.8 \pm 2.5$ & $174 \pm 23$ & $0.69 \pm 0.12$ & $1.7 \pm 0.20$ \\
\hline
\end{tabular}

$* P<0.05$ versus Pre

** $P<0.01$ versus Pre

The data of $\mathrm{BV}$ and $\mathrm{PV}$ show the percentage changes $(\% \Delta)$, compared with the volume at 0 -h bed rest

the increase observed upon standing. BP did not change significantly. Upon standing, $\mathrm{mBP}$ was significantly increased (Table 2).

Figure 2 summarizes comparative effects of $100 \mathrm{mmHg}$ KAATSU on hemodynamic parameters in the seated position before bed rest and at $6^{\circ}$ head-down tilt bed rest during the simulated weightlessness. HR (Fig. 2a) and sBP
(Fig. 2b) during KAATSU in the simulated weightlessness were not significantly different from those in the seated position before bed rest. On the other hand, KAATSU markedly reduced SV (Fig. 2c) and $\mathrm{CO}$ (Fig. 2d) with an increase in TPR (Fig. 2e) during the simulated weightlessness, compared to the seated position before bed rest.
Fig. 2 Comparative effects of KAATSU $(100 \mathrm{mmHg})$ on the hemodynamic parameters in the seated position before bed rest and $6^{\circ}$ head-down position $24 \mathrm{~h}$ after bed rest. Effects of KAATSU (100 mmHg) on HR (a), $\operatorname{sBP}(\mathbf{b}), \mathrm{SV}(\mathbf{c}), \mathrm{CO}(\mathbf{d})$ and TPR (e) are illustrated. All values are means \pm SEM obtained from seven subjects. * $P<0.05$, ** $P<0.01$
A

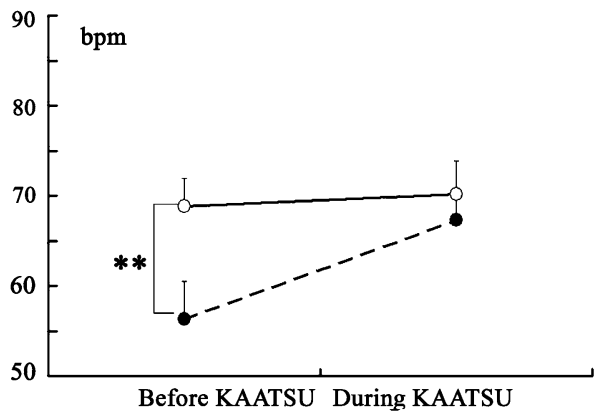

B

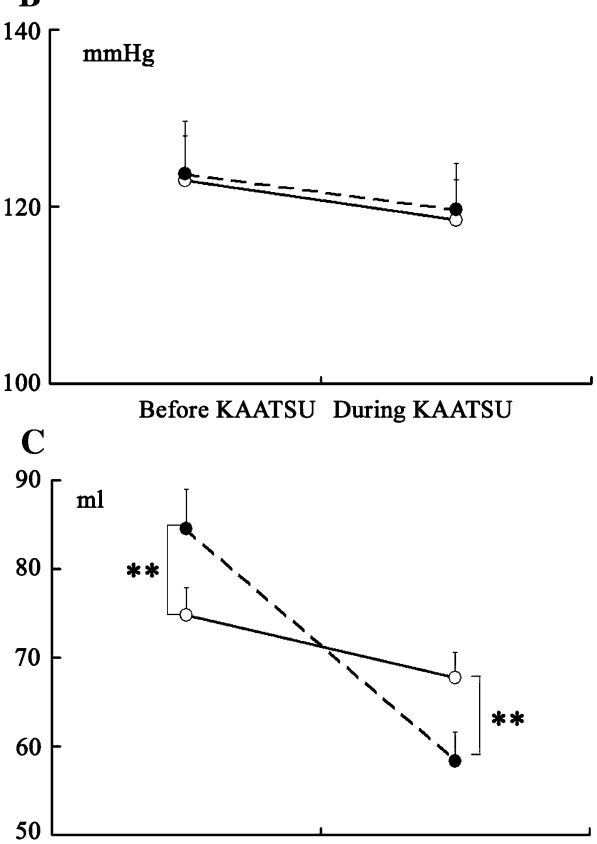

Before KAATSU During KAATSU

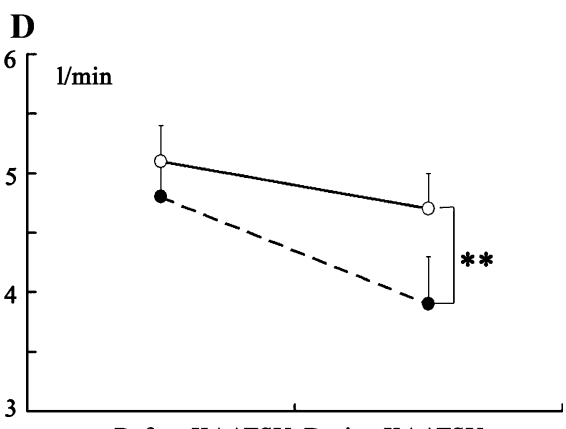

Before KAATSU During KAATSU

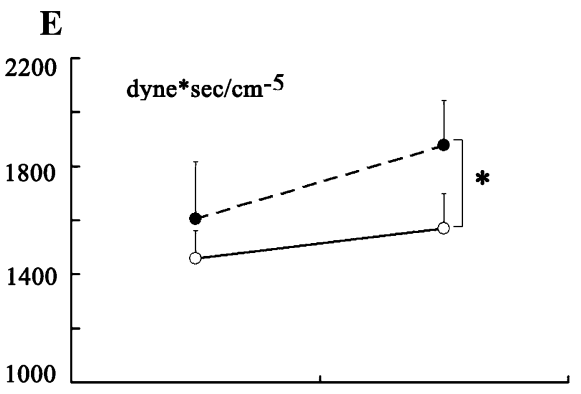

Before KAATSU During KAATSU

$-100 \mathrm{mmHg}$ sitting

$\rightarrow-100 \mathrm{mmHg}$ bed rest 
NOR, PRA, and ADH were all significantly increased during 100-mmHg KAATSU, but NOR only significantly increased with $50 \mathrm{mmHg}$ KAATSU (Table 3). All values returned to pre-KAATSU levels during the recovery period.

$\mathrm{HF}_{\mathrm{RR}}$ (Fig. 3b), determined from the power spectra of HR variability (HRV; Fig. 3a), was reduced with $100 \mathrm{mmHg}$ KAATSU $(P<0.05)$ and tended to decrease with $50 \mathrm{mmHg}$ KAATSU $(P=0.17)$. In contrast, the $\mathrm{LF}_{\mathrm{RR}} \cdot \mathrm{HF}_{\mathrm{RR}}{ }^{-1}$ component was increased during each KAATSU trial (Fig. 3c). All changes returned to preKAATSU levels during the recovery period. Upon standing, $\mathrm{HF}_{\mathrm{RR}}$ decreased significantly and equivalently to the changes with KAATSU (Fig. 3b), however, the increase in $\mathrm{LF}_{\mathrm{RR}} / \mathrm{HF}_{\mathrm{RR}}$ was greater than that observed during KAATSU (Fig. 3c).

\section{Discussion}

The present study shows that following $6^{\circ}$ head-down tilt bed rest for $24 \mathrm{~h}$, a model simulating microgravity effects on the cardiovascular system, KAATSU blood flow restriction reproduces the effects of standing on $\mathrm{HR}, \mathrm{SV}$, NOR, ADH, PRA, etc., thus stimulating a gravity-like stress during simulated weightlessness. However, syncope due to lower extremity blood pooling and subsequent reduction of venous return may be induced during KAATSU in microgravity as reported in cases of LBNP.

During $6^{\circ}$ head-down tilt bed rest, a model to simulate zero $\mathrm{G}$ eliminates the normal downward hydrostatic pressure gradients and causes an immediate central fluid shift from lower extremities toward the thoracic-cephalic region (Norsk et al. 1993). The central hypervolemia affects hormonal regulation of fluid excretion and stimulates central cardiac volume receptors, resulting in a loss of plasma volume (Norsk et al. 1993; Duranteau et al. 1995). In the present study, $24 \mathrm{~h} 6^{\circ}$ head-down tilt bed rest resulted in a total urine volume $\left(2,052 \pm 249 \mathrm{ml} \mathrm{d}^{-1}\right)$ that was in excess of fluid intake $\left(1,320 \pm 67 \mathrm{ml} \mathrm{d}^{-1}\right)$. Then, blood and plasma volume was decreased by a mean value of 4.4 and $7.9 \%$, respectively. This fluid volume loss was reflected in the significant decrease in body mass and IVC diameter, which was compatible with the previous papers (Nixon et al. 1979; Gaffney et al. 1985). Furthermore, head-down bed rest induces an initial cephalad-fluid shift with an inhibition of the renin-angiotensin system and ADH. Hughson et al. (1995) showed a 40\% decrease in PRA after 10-h head-down tilt. In the present study, concentration of PRA and ADH tended to decrease following $24 \mathrm{~h}$ of $6^{\circ}$ head-down tilt bed rest, but not statistically different. NOR $\left(201 \pm 45\right.$ to $157 \pm 24 \mathrm{pg} \mathrm{ml}^{-1}$, $P=0.09$ ) also tended to decrease as reported throughout space flight missions and bed rest (Leach et al. 1983). Thus, it is likely that physiological alterations caused by $6^{\circ}$ headdown tilt bed rest condition observed here mimicked the weightless condition of space flight.

During an orthostatic stress, part of the blood and plasma volume can pool in the capillary bed of the legs, and subsequently, SV decreases because of reduced venous return. KAATSU applied to both the legs also decreased venous return by pooling blood into the vascular and extracellular compartment of the legs and ultimately induced the hemodynamic alterations comparable to standing as previously reported (Iida et al. 2007). A decrease in SV induced by KAATSU (150-200 $\mathrm{mmHg}$ ) in the seated position was larger than that induced by standing. Similarly, during the simulated weightlessness, the
Fig. 3 Effects of KAATSU on heart rate variability (HRV) after $24-\mathrm{h} 6^{\circ}$ bed rest. a The time courses of HRV during KAATSU. Note that during KAATSU $(100 \mathrm{mmHg}), \mathrm{LF}_{\mathrm{RR}}$ increased, compared with the control, while $\mathrm{HF}_{\mathrm{RR}}$ decreased. b Effects of orthostatic stress (standing) and KAATSU on $\mathrm{HF}_{\mathrm{RR}}$. c Effects of orthostatic stress (standing) and KAATSU on $\mathrm{HF}_{\mathrm{RR}} \cdot \mathrm{LF}_{\mathrm{RR}}{ }^{-1}$. All values are means \pm SEM obtained from seven subjects. $* P<0.05$, ** $P<0.01$ versus control (pre)
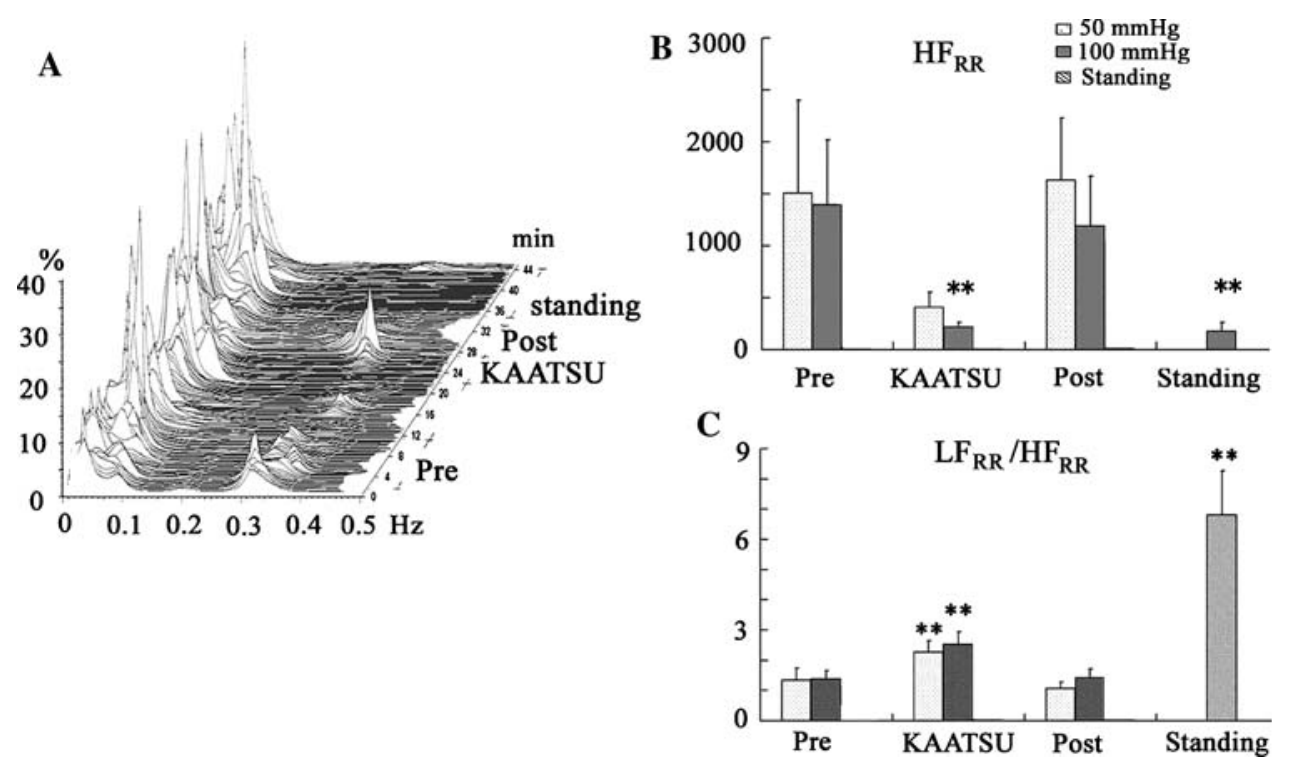
decrease in SV induced by $100 \mathrm{mmHg}$ KAATSU was approximately equivalent to that induced by standing. The effects of $50 \mathrm{mmHg}$ KAATSU on SV were less than $100 \mathrm{mmHg}$ KAATSU. Thus, the magnitude of venous pooling, reduced venous return, and the decrement of SV is greatly dependent upon the level of the KAATSU (Iida et al. 2007). While orthostatic stress decreases SV, and induces hypotensive stimuli, $\mathrm{CO}$ and $\mathrm{BP}$ are maintained by an increased HR and TRP via arterial and cardiopulmonary baroreceptor control of circulation. Under the hypovolemic condition of 24-h bed rest, KAATSU (50 and $100 \mathrm{mmHg}$ ) induced a larger decrease in SV with an increase in HR and TRP. Thus, during KAATSU, arterial baroreceptors as well as cardiopulmonary baroreceptors were unloaded (Furlan et al. 2001; Brown et al. 2003), which mimicked orthostatic stress. During actual space flight, the Russian physicians have already used a unique method for a countermeasure, called "bracelets" to reduce edema and venous stasis in the cephalic region by pooling blood in the vascular and extravascular compartments of the legs (Lindgren et al. 1998; Arbeille et al. 1999; Millet et al. 2000). This method applies a pressure of $\sim 30 \mathrm{mmHg}$, proposing that the degree of venous pooling induced by the bracelets is much lower than that observed in KAATSU, where the cuff pressure of $100-250 \mathrm{mmHg}$ is used to restrict muscle blood flow and increase muscle mass. Regarding autonomic nervous responses to KAATSU, $\mathrm{HF}_{\mathrm{RR}} \cdot \mathrm{LF}_{\mathrm{RR}}{ }^{-1}$, a marker of sympathetic activity, and the serum concentration of NOR, a well-known neurotransmitter released from sympathetic nerve, increased, which depended on the pressure of KAATSU. On the other hand, $\mathrm{HF}_{\mathrm{RR}}$, a marker of parasympathetic activity, decreased with KAATSU. Overall, it also indicates that during KAATSU, the arterial baroreceptor unloading is the dominant phenomenon leading to sympathetic excitation during the simulated weightlessness. The renin-angiotensin system is activated by an orthostatic stress (Duranteau et al. 1995). And, orthostatic intolerance after bed rest or spaceflight may partly result from impaired vasoconstriction, possibly due to a decreased secretion of renin-angiotensin (Fortney et al. 1991). During $6^{\circ}$ head-down bed rest, the secretion of PRA and $\mathrm{ADH}$ was increased during KAATSU, depending on the degree of the pressure. From these observations, it is likely that the application of KAATSU, when using a proper pressure, on both the thighs partly simulates hemodynamic, systemic cardiovascular, autonomic nervous and hormonal effects of orthostasis during the simulated weightlessness.

Both LBNP and KAATSU induce the retention of blood flow in lower extremities, and induce subsequent hemodynamic changes such as decreased $\mathrm{SV}$ and $\mathrm{CO}$ and increased TPR (Stevens and Lamb 1965; Güell et al. 1990, 1992; Melchior et al. 1994; Murthy et al. 1994; Lee et al.
1997; Watenpaugh et al. 2000; Iida et al. 2007). The mechanism triggered by these methods (negative pressure vs. KAATSU) is quite different. However, the key physiological features of both the methods are lower extremity blood pooling, reduction of venous return to the heart, and subsequent hemodynamic changes including increased autonomic nervous system activation (Stevens and Lamb 1965; Tomaselli et al. 1987; Lathers and Charles 1993). Therefore, the effects of KAATSU and LBNP on hemodynamic parameters previously reported (Frey et al. 1986; Sandler et al. 1988; Tomaselli et al. 1990; Lathers and Charles 1993; Melchior et al. 1994; Iida et al. 2007) are compared and summarized in Table 4. Application of LBNP $(-30,-40$ and $-50 \mathrm{mmHg})$ decreases $\mathrm{SV}$ in a pressure-dependent manner. $50 \mathrm{mmHg}$ LBNP simulates systemic cardiovascular effects of orthostasis in $1 \mathrm{G}$ (Wolthuis et al. 1974). On the other hand, KAATSU (150$200 \mathrm{mmHg}$ ) in the supine position (Iida et al. 2007) decreases $\mathrm{SV}$, which is comparable to standing and LBNP of -30 to $-40 \mathrm{mmHg}$ as shown in Table 4 . The present study showed that during actually simulated weightlessness ( $6^{\circ}$ head-down tilt for $24 \mathrm{~h}$ ), KAATSU $100 \mathrm{mmHg}$ on both the thighs produced $32 \%$ reduction of $\mathrm{SV}$, which was equal to that observed in LBNP $(-40 \mathrm{mmHg})$. Thus, KAATSU appears to effectively induce pressure-dependent retention of blood flow, and induce subsequent hemodynamic changes like LBNP.

Syncopal attack has been reported to occur in LBNP, especially when using high pressure more than $-40 \mathrm{mmHg}$ (Stevens and Lamb 1965). The mechanisms in the occurrence of syncope remain unsettled, but several factors such as blood pooling in the extremities and splanchnic territory, and the deterioration of distal leg arterial and venous compliance have been proposed. The present study also showed that during actually simulated weightlessness, one subject had presyncope due to a drop of blood pressure during $100 \mathrm{mmHg}$ KAATSU. This subject had no signs or verbal complaints associated with KAATSU (100$200 \mathrm{mmHg}$ ) in the seated position before bed rest. And, KAATSU markedly reduced SV and CO with an increase in TPR during the simulated weightlessness, compared with the seated position before bed rest, proposing that blood pooling in the extremities under hypovolemia developed during bed rest may be partly involved in the induction of presyncope. Thus, the occurrence of syncope should be taken into account during the actual space flight, when the KAATSU training is used during space flight. But, the KAATSU training is usually combined with exercises, and during exercise, the skeletal muscle pumping mechanism partially counteracts accumulation of blood in hyperemic lower extremities like LBNP (Eiken et al. 1986; Watenpaugh et al. 1994), where dynamic leg exercise combined with LBNP has been reported to double 


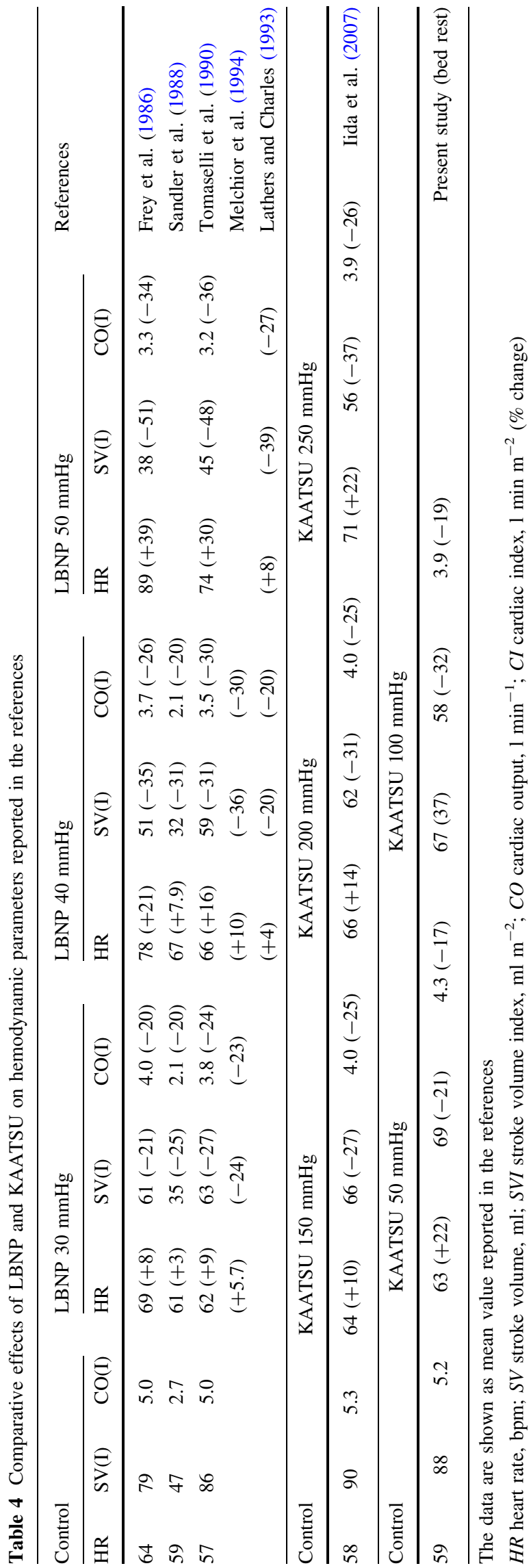

LBNP tolerance (Watenpaugh et al. 1994). In a similar way, leg exercise combined with KAATSU may increase the tolerance for developing syncope and then prevent its occurrence.

Currently, astronauts practice $2-3 \mathrm{~h}$ of intensive exercise using treadmill, ergometer and resistance machines. These time-consuming countermeasures decrease plasma volume loss, and partly prevent muscle atrophy and bone loss. But, they cannot prevent astronauts from cardiovascular deconditioning. Therefore, alternate countermeasure strategies are necessary. Now, the most effective countermeasure regimen appears to be a gravitation-like stress combined with exercises. LBNP combined with treadmill has been shown to be a useful method to prevent orthostatic intolerance after space flight or during bed rest periods, probably through its effect as orthostatic stimulus (Güell et al. 1992; Murthy et al. 1994; Buckey et al. 1996; Lee et al. 1997, 2007; Watenpaugh et al. 2000; Schneider et al. 2002). It has been reported to maintain sub-maximal exercise responses such as maximal heart rate, respiratory exchange ratio, and ventilation, aerobic fitness and sprint speed, then preventing orthostatic intolerance during bed rest (Lee et al. 1997; Watenpaugh et al. 2000). In the present study, KAATSU appears to effectively induce pressure-dependent retention of blood flow, and induce subsequent hemodynamic changes like LBNP. The KAATSU training has been reported to result in an increase in muscle mass and muscular strength without any complications (Takarada et al. 2000; Abe et al. 2006; Fujita et al. 2007). And, it can be applied to all types of exercises including treadmill, ergometer, and resistance machines, which can be easily used by astronauts. Thus, the KAATSU training may provide an appropriate countermeasure for cardiovascular deconditioning as well as musculoskeletal decline associated with weightlessness. However, further studies are needed to clarify this interesting possibility as well as the safety during the long-term weightlessness.

Acknowledgments This study is partly financially supported by Japan Aerospace Explosion Agency and the University of Tokyo.

Open Access This article is distributed under the terms of the Creative Commons Attribution Noncommercial License which permits any noncommercial use, distribution, and reproduction in any medium, provided the original author(s) and source are credited.

\section{References}

Abe T, Kearns CF, Sato Y (2006) Muscle size and strength are increased following walk training with restricted venous blood flow from the leg muscle, Kaatsu-walk training. J Appl Physiol 100:1460-1466. doi:10.1152/japplphysiol.01267.2005 
Arbeille P, Herault S, Fomina G, Roumy J, Alferova I, Gharib C (1999) Influences of thigh cuffs on the cardiovascular system during 7-day head-down bed rest. J Appl Physiol 87:2168-2176

Brown CM, Hecht MJ, Neundörfer B, Hilz MJ (2003) Effects of lower body negative pressure on cardiac and vascular responses to carotid barorelex stimulation. Physiol Res 52:637-645

Buckey JC Jr, Lane LD, Levine BD, Watenpaugh DE, Wright SJ, Moore WE et al (1996) Orthostatic intolerance after spaceflight. J Appl Physiol 81:7-18

Duranteau J, Pussard E, Berdeaux A, Giudicelli JF (1995) Role of the renin-angiotensin system in systemic and regional vascular responses to orthostatic stress in healthy volunteers. Fundam Clin Pharmacol 9:479-487

Eiken O, Lind F, Bjurstedt H (1986) Effects of blood volume distribution on ventilatory variables at rest and during exercise. Acta Physiol Scand 127:507-512

Fortney SM, Hyatt KH, Davis JE, Vogel JM (1991) Changes in body fluid compartments during a 28-day bed rest. Aviat Space Environ Med 62:97-104

Frey MAB, Mathes KL, Hoffler GW (1986) Cardiovascular responses of women to lower body negative pressure. Aviat Space Environ Med 57:531-538

Fritsch-Yelle JM, Whitson PA, Bondar RL, Brown TE (1996) Subnormal norepinephrine release relates to presyncope in astronauts after spaceflight. J Appl Physiol 81:2134-2141

Fujita S, Abe T, Drummond MJ, Cadenas JG, Dreyer HC, Sato Y et al (2007) Blood flow restriction during low-intensity resistance exercise increases S6K1 phosphorylation and muscle protein synthesis. J Appl Physiol 103:903-910. doi:10.1152/japplphysiol. 00195.2007

Furlan R, Jacob G, Palazzolo L, Rimoldi A, Diedrich A, Harris PA et al (2001) Sequential modulation of cardiac autonomic control induced by cardiopulmonary and arterial baroreflex mechanisms. Circulation 104:2932-2937. doi:10.1161/hc4901.100360

Gaffney FA, Nixon JV, Karlsson ES, Campbell W, Dowdey AB, Blomqvist CG (1985) Cardiovascular deconditioning produced by 20 hours of bed rest with head-down tilt $\left(-5^{\circ}\right)$ in middleaged healthy men. Am J Cardiol 56:634-638. doi:10.1016/ 0002-9149(85)91025-2

Güell A, Braak L, Pavy-Le Traon A, Gharib C (1990) Cardiovascular deconditioning during weightlessness stimulation and the use of lower body negative pressure as a countermeasure to orthostatic intolerance. Acta Astronaut 21:667-672. doi:10.1016/0094-5765 (90)90078-Y

Güell A, Cornac A, Faurat MM, Gauquelin G, Pavy-Le Traon A, Gharib C (1992) Lower body negative pressure as a countermeasure against orthostatic intolerance for long term space flight. Acta Astronaut 27:103-107. doi:10.1016/0094-5765(92)90185-L

Herault S, Fomina G, Alferova I, Kotovskaya A, Poliakov V, Arbeille P (2000) Cardiac, arterial and venous adaptation to weightlessness during 6-month MIR spaceflights with and without thigh cuffs (bracelets). Eur J Appl Physiol 81:384-390. doi: 10.1007/s004210050058

Hughson RL, Maillet A, Gauquelin G, Arbeille P, Yamamoto Y, Gharib C (1995) Investigation of hormonal effects during 10-h head-down tilt on heart rate and blood pressure variability. J Appl Physiol 78:583-596

Iida H, Kurano M, Takano H, Kubota N, Morita T, Meguro K et al (2007) Hemodynamic and neurohumoral responses to the restriction of femoral blood flow by KAATSU in healthy subjects. Eur J Appl Physiol 100:275-285. doi:10.1007/ s00421-007-0430-y

Lathers CM, Charles JB (1993) Use of lower body negative pressure to counter symptoms of orthostatic intolerance in patients, bed rest subjects, and astronauts. J Clin Pharmacol 33:1071-1085
Leach CS, Altchuler SI, Cintron-Trevino NM (1983) The endocrine and metabolic responses to space flight. Med Sci Sports Exerc 15:432-440. doi:10.1249/00005768-198315050-00016

Lee SM, Bennett BS, Hargens AR, Watenpaugh DE, Ballard RE, Murthy G et al (1997) Upright exercise or supine lower body negative pressure exercise maintains exercise responses after bed rest. Med Sci Sports Exerc 29:892-900. doi:10.1097/00005768199707000-00008

Lee SM, Schneider SM, Boda WL, Watenpaugh DE, Macias BR, Meyer RS et al (2007) Supine LBNP exercise maintains exercise capacity in male twins during 30-d bed rest. Med Sci Sports Exerc 39:1315-1326. doi:10.1249/mss.0b013e31806463d9

Lindgren KN, Kraft D, Ballard RE, Tucker A, Hargens AR (1998) Venoconstrictive thigh cuffs impede fluid shifts during simulated microgravity. Aviat Space Environ Med 69:1052-1058

Melchior FM, Srinivasan RS, Thullier PH, Clere JM (1994) Simulation of cardiovascular response to lower body negative pressure from 0 to $-40 \mathrm{mmHg}$. J Appl Physiol 77:630-640

Millet C, Custaud MA, Allevard AM, Gharib C, Gauquelin-Koch G, Fortrat JO (2000) Adaptations to a 7-day head-down bed rest with thigh cuffs. Med Sci Sports Exerc 32:1748-1756. doi: 10.1097/00005768-200010000-00014

Murthy G, Watenpaugh DE, Ballard RE, Hargens AR (1994) Exercise against lower body negative pressure as a countermeasure for cardiovascular and musculoskeletal deconditioning. Acta Astronaut 33:89-96. doi:10.1016/0094-5765(94)90112-0

Nicogossian A, Pool S, Sawin C (1995) Status and efficacy of countermeasures to physiological deconditioning from space flight. Acta Astronaut 36:393-398. doi:10.1016/0094-5765(95) 00123-9

Nixon JV, Murray RG, Bryant C, Johnson RL Jr, Mitchell JH, Holland OB et al (1979) Early cardiovascular adaptation to stimulated zero gravity. J Appl Physiol 46:541-548

Norsk P, Stadeager C, Johansen LB, Warberg J, Bie P, Foldager N et al (1993) Volume-homeostatic mechanisms in humans during a 12-h posture change. J Appl Physiol 75:349-356

Sandler H, Popp RL, Harrison DC (1988) The hemodynamic effects of repeated bed rest exposure. Aviat Space Environ Med 59:1047-1054

Schneider SM, Watenpaugh DE, Lee SM, Ertl AC, Williams WJ, Ballard RE et al (2002) Lower-body negative-pressure exercise and bed-rest-mediated orthostatic intolerance. Med Sci Sports Exerc 34:1446-1453. doi:10.1097/00005768-20020900000008

Stevens PM, Lamb LE (1965) Effects of lower body negative pressure on the cardiovascular system. Am J Cardiol 16:506-515. doi: 10.1016/0002-9149(65)90027-5

Takano H, Morita T, Iida H, Asada K, Kato M, Uno K et al (2005) Hemodynamic and hormonal responses to a short-term low-intensity resistance exercise with the reduction of muscle blood flow. Eur J Appl Physiol 95:65-73. doi:10.1007/ s00421-005-1389-1

Takarada Y, Takazawa H, Sato Y, Takebayashi S, Tanaka Y, Ishii N (2000) Effects of resistance exercise combined with moderate vascular occlusion on muscle function in humans. J Appl Physiol 88:2097-2106

Tomaselli CM, Frey MA, Kenney RA, Hoffler GW (1987) Hysteresis in response to descending and ascending lower-body negative pressure. J Appl Physiol 63:719-725

Tomaselli CM, Frey MA, Kenney RA, Hoffler W (1990) Effect of a central redistribution of fluid volume on response to lower-body negative pressure. Aviat Space Environ Med 61:38-42

Watenpaugh DE, Ballard RE, Stout MS, Murthy G, Whalen RT, Hargens AR (1994) Dynamic leg exercise improves tolerance to lower body negative pressure. Aviat Space Environ Med $65: 412-418$ 
Watenpaugh DE, Ballard RE, Schneider SM, Lee SM, Ertl AC, William JM et al (2000) Supine lower body negative pressure exercise during bed rest maintains upright exercise capacity. J Appl Physiol 89:218-227
Wolthuis RA, Bergman SA, Nicogossian AE (1974) Physiological effects of locally applied reduced pressure in man. Physiol Rev 54:566-595 